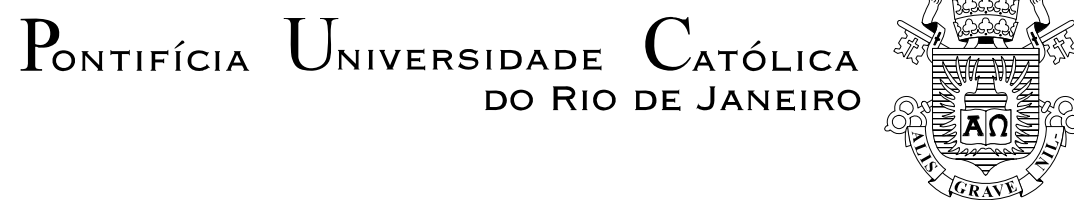

Maria das Graças de Almeida Chagas

\title{
A Inserção do Designer de Games na Indústria Brasileira de Jogos Eletrônicos
}

Tese de Doutorado

Tese apresentada ao Programa de Pós-Graduação em Design da PUC-Rio como requisito parcial para obtenção do grau de Doutor em Design.

Orientadora: Rejane Spitz

Rio de Janeiro

Setembro de 2009 


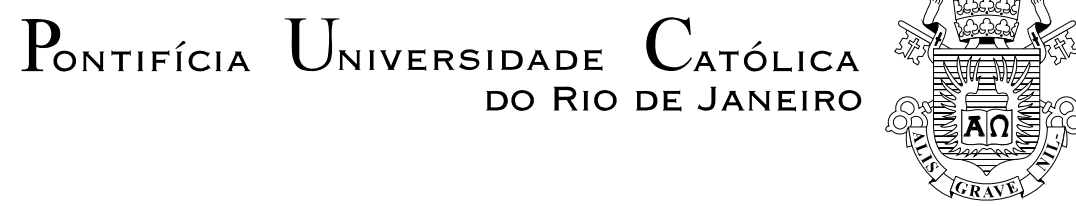

Maria das Graças de Almeida Chagas

\section{A Inserção do Designer de Games na Indústria Brasileira de Jogos Eletrônicos}

Tese apresentada ao Programa de Pós-Graduação em Design da PUC-Rio como requisito parcial para obtenção do grau de Doutor em Design. Aprovada pela Comissão Examinadora abaixo assinada.

Rejane Spitz Orientador Departamento de Artes e Design - PUC-Rio

André Luiz Battaiola UFPR

Esteban Walter Gonzalez Clua UFF

Bruno Feijó Departamento de Informática - PUC-Rio

Rita Maria de Souza Couto Departamento de Artes e Design - PUC-Rio

Prof. Paulo Fernando Carneiro de Andrade Coordenador Setorial do Centro de Teologia e Ciências Humanas - PUC-Rio 
Todos os direitos reservados. É proibida a reprodução total ou parcial do trabalho sem autorização da universidade, da autora e da orientadora.

\section{Maria das Graças de Almeida Chagas}

Graduou-se em Processamento de Dados pela Universidade Federal do Ceará em 1985. Concluiu especialização em Electronic Imaging em 1991, no Jordanstone College of Art University of Dundee, Escócia, com bolsa de cheevening student do British Council. Mestre em Design pela PUC-Rio em 2002. É Supervisora de Mídia Digital e Professora de Computação Gráfica e Design de Jogos Eletrônicos do curso de Graduação em Design, do Departamento de Artes e Design da PUC-Rio, onde também participa de projetos de pesquisa. É Chefe da Divisão de Multimídia do RDC/PUC-Rio, onde coordena projetos Hipermídia, entre eles o Site da Universidade. Trabalhando com fotografia na década de 80 e com animação, vídeo e técnicas interativas a partir da década de 90, participou de diversas exposições individuais e coletivas. É uma das fundadoras do Simpósio Brasileiro de Jogos e Entretenimento Digital - SBGames - congresso anual da Comissão Especial de Jogos e Entretenimento Digital da Sociedade Brasileira de Computação - SBC.

Ficha Catalográfica

Chagas, Maria das Graças de Almeida

A inserção do designer de games na indústria brasileira de jogos eletrônicos / Maria das Graças de Almeida Chagas ; orientadora: Rejane Sptiz. - 2009. 143 f. : il. (clor.) ; $30 \mathrm{~cm}$

Tese (Doutorado em Design) - Pontifícia Universidade Católica do Rio de Janeiro, Departamento de Artes e Design, Rio de Janeiro, 2009.

Inclui bibliografia

1. Artes - Teses. 2. Design. 3. Design de games. 4. Designer de games. 5. Game design. 6. Game designer. 7. Perfil profissional. 8. Formação. I. Spitz, Rejane. II. Pontifícia Universidade Católica do Rio de Janeiro. Departamento de Artes e Design. III. Título. 


\section{Agradecimentos}

A todos aqueles que me são próximos e especiais, por me apoiarem, me incentivarem, me inspirarem e compreenderem meu isolamento e minha ausência em suas vidas ao longo de muitas etapas da realização deste trabalho.

A minha grande amiga e orientadora Profa. Rejane Spitz, pelo apoio, incentivo e por tudo que me ensinou.

Aos meus colegas de trabalho do RDC, em especial ao Prof. Jose Raimundo Oliveira, nosso Diretor, cujo apoio foi imprescindível para a realização deste trabalho, e a minha equipe da Divisão de Multimídia (Soraya, Dani, Flavia, Gustavo, Letícia e Vitor), cujo apoio foi igualmente importante ao longo de toda a jornada de realização desta pesquisa. Um agradecimento especial também a Márcia Campos, chefe da Divisão de Apoio Administrativo e Operacional, e seus funcionários.

Aos professores, funcionários e alunos do Departamento de Artes e Design da PUC-Rio, pelos atos e palavras de incentivo.

Aos professores e colegas de trabalho da área de jogos eletrônicos da PUC-Rio e de diversas universidades brasileiras, cuja convivência muito me ensinou e contribuiu para a realização desta pesquisa.

Aos empresários e executivos da indústria brasileira de jogos eletrônicos entrevistados para esta pesquisa, que gentilmente se dispuseram a prestar uma grande contribuição ao trabalho por mim realizado.

Aos Coordenadores de pós-graduação a nível Departamental, Setorial e Central da PUC-Rio.

A PUC-Rio, que me proporcionou a oportunidade de realizar este curso

\section{A Deus!!!!}




\section{Resumo}

Chagas, Maria das Graças de Almeida; Spitz, Rejane (Orientadora). A Inserção do Designer de Games na Indústria Brasileira de Jogos Eletrônicos. Rio de Janeiro, 2009. 143p. Tese de Doutorado - Departamento de Artes e Design, Pontifícia Universidade Católica do Rio de Janeiro - PUC-Rio.

O presente trabalho trata da inserção do Designer de Games na indústria brasileira de jogos eletrônicos que, como um setor em amadurecimento e crescimento no Brasil, apresenta-se como um campo de atuação ainda pouco investigado, no que se relaciona a esse profissional. O Designer de Games tem um papel central no processo de desenvolvimento de um jogo eletrônico. Foi realizado um levantamento dos cursos voltados para o ensino de Design de Games no Brasil e foram entrevistados empresários e executivos da indústria brasileira de jogos eletrônicos. A partir da percepção dos entrevistados, traçou-se um panorama das características da indústria brasileira de jogos eletrônicos em seu momento atual no que diz respeito à esfera de atuação do Designer de Games, e mapeou-se aspectos do perfil desse profissional considerados importantes para sua inserção nessa indústria. A investigação conduzida permitiu observar importantes questões a respeito de como a formação acadêmica e o perfil profissional do Designer de Games tem sido percebida pela indústria brasileira de jogos eletrônicos. Através do trabalho realizado foi possível examinar as perspectivas atuais de inserção do Designer de Games na indústria brasileira de jogos eletrônicos e projetar possibilidades para ampliação da inserção hoje existente. A pesquisa contribui para ampliar o conhecimento que se tem a respeito do panorama de trabalho no qual alunos formados em Design de Games estarão inseridos, caso optem por seguir uma carreira de Designer de Games no Brasil, e para iluminar a discussão a respeito da inserção desse profissional na indústria brasileira de jogos eletrônicos, ao trazer à tona novos questionamentos e apontar direções para futuros desdobramentos.

\section{Palavras-chave}

Design; Design de Games; Designer de Games; Game Design; Game Designer; perfil profissional; formação; inserção; atuação; indústria brasileira de jogos eletrônicos; jogos digitais; produto; processo de projeto 


\section{Abstract}

Chagas, Maria das Graças de Almeida; Spitz, Rejane (Advisor). The Game Designer's insertion in the Brazilian Industry of Electronic Games. Rio de Janeiro, 2009. 143p. Thesis - Departamento de Artes e Design, Pontifícia Universidade Católica do Rio de Janeiro - PUC-Rio.

This research work deals with the insertion of the Game Designer in the Brazilian Industry of Electronic Games. As a developing industry it represents a professional field for this career with nearly no research work done about it. The Game Designer has a central role in the electronic game Design process. A survey was conducted to list College and University degree courses in Game Design in Brasil and entrepreneurs and executives from the Brazilian Industry of Electronic Games were interviewed. Based on the data collected in the interviews, a frame of the Brazilian Industry of Electronic Games' characteristics was produced, with a focus on the scope of the Game Designer's tasks and assignments. The Game Designer's professional profile characteristics to be important in his/her insertion in the industry were also mapped. The investigation allowed to observe important issues related to how the Game Designer's academic background and professional profile has been perceived by the Brazilian Industry of Electronic Games. The research also examined the Game Designer's current and future possibilities and perspectives to insert her/himself into the Brazilian Industry of Electronic Games.. The research contributes to broaden the understanding of job perspectives for Game Design graduate students in Brazil. By bringing to light new questions about the insertion of the Game Designer in the Brazilian Industry of Electronic Games, this research might illuminate and inspire new directions for future investigations on this subject.

\section{Key-words}

Design; Game Design; Game Designer; profile; academic background; insertion; professional performance; Brazilian industry of electronic games; digital games; product; Design process 


\section{Sumário}

1- Introdução ..................................................................................... 10

2-. Referencial teórico ........................................................................... 22

2.1- Definindo “Jogos Eletrônicos” ............................................................. 22

2.2- O jogo eletrônico como produto industrial $\quad$............................................ 24

2.3- Funções e cargos em equipes de projetos de jogos eletrônicos e $\quad$....... $\quad 27$ as atribuições do Designer de Games no processo de projeto

2.4- O Designer de Games na indústria de jogos eletrônicos ..................... 30

2.5- O ensino de Design de Games e a carreira de Designer de Games .... 33

3- Questões metodológicas .................................................................. 36

3.1- Problema …................................................................................... 36

3.2- Levantamento Bibliográfico .............................................................. 38

3.3- Levantamento sobre cursos de nível superior no Brasil voltados $\quad$....... $\quad 39$ para o ensino de Design de Games

3.4- As entrevistas .............................................................................. 40

3.5- A análise dos dados ............................................................................. 42

4- Cursos de nível superior no Brasil voltados para o ensino de ........... 47 Design de Games

5- Percepções de empresários e executivos sobre a esfera de atuação ......... do Designer de Games na indústria brasileira de jogos eletrônicos e o perfil desse profissional

5.1- A esfera de atuação do Designer de Games ........................................ 53

5.1.1- Formação acadêmica dos Designers de Games em atuação no ........ 54 Brasil: diversidade

5.1.2- Nível de maturidade e potencial de absorção de profissionais: o mercado é pequeno, instável e imaturo

5.1.3- Reconhecimento do papel do Designer de Games

5.1.4- Potencial de crescimento e de projeção internacional 
5.2- Características do perfil profissional do Designer de Games .............. $\quad 70$

5.2.1- Repertório vasto em games, conhecimento de sua evolução $\quad$............. $\quad 70$ histórica e paixão por jogos

5.2.2- Conhecimentos de metodologias de desenvolvimento de projetos ..... e visão de processo

5.2.3- Visão de mercado e de negócios .........................................................

5.2.4- O Designer de Games como um criador de experiências ................. $\quad 80$

5.2.5- Atitude proativa e empreendedora ..................................................... 82

5.2.6- Experiência prática ......................................................................... 84

5.2.7- Formação acadêmica e embasamento teórico do Designer de Games 87

5.2.8- Conhecimento em diversas áreas, em especial em Artes e .............. 94 Tecnologia para Games

5.2.9- Saber comunicar com clareza idéias e conceitos $\quad$............................. 97

5.2.10- Ter um bom relacionamento interpessoal e saber trabalhar em $\quad$...... 99 equipe

6- A inserção do Designer de Games na indústria brasileira de jogos eletrônicos

6.1- Inserção em um nível abrangente no processo de projeto 106

6.2- Inserção em níveis específicos do processo de projeto

6.2.1- Inserção na etapa de Formulação de Critérios

6.2.2- Inserção na etapa de Tradução de Informação

6.2.3- Inserção na etapa de Geração de Conceito

6.2.4- Inserção na etapa de Detalhamento, Geração de Esboços, .

Estruturação e Refinamento

6.2.5- Inserção na etapa de Lançamento do Jogo

6.3 - Atividades envolvendo o crescimento da indústria brasileira de ........ jogos eletrônicos e da profissão de Designer de Games no Brasil

7- Considerações Finais

Referências 
ANEXO II- Roteiro de questões para a realização das entrevistas

ANEXO III- Tabela do Levantamento dos Cursos de nível superior

no Brasil para formação de Designers de Games 